\title{
PUBLIC PARTICIPATION AND PRIVATISATION IN ENVIRONMENTAL MATTERS: AN ASSESSMENT OF THE AARHUS CONVENTION
}

\author{
Jonas Ebbesson*
}

\begin{abstract}
In using the Aarhus Convention as a reference, this article examines the tension between two developments of environmental governance in the last decades: (i) the strengthening of participatory rights of members of the public in environmental decision-making; and (ii) the privatisation and outsourcing of resources, services and functions related to natural resources and the environment. It observes that privatisation may significantly affect the scope of participatory rights in environmental matters, including the right to access to information. Yet, the broad conception of 'public authority' in the Aarhus Convention implies a right to access to information also when corporations, as a result of privatisation, perform public administrative functions or have public responsibilities or functions in relation to the environment. The right to participate in decision-making also remains when resources and services are privatised. The Aarhus Convention does not exclude the possibility of delegating certain responsibilities in decision-making procedures to different bodies and private actors, but only to the extent that sufficient impartiality is ensured to guarantee proper conduct during the public participation procedure. In such situations, all standards for public participation apply in full. Finally, the Aarhus Convention precludes almost all attempts to privatise any function relating to access to justice. The article concludes that the effectiveness of participatory rights in case of privatisation not only depends on formal compliance with the Aarhus Convention standards, but also on the general domestic legal setting surrounding privatisation.
\end{abstract}

Keywords: public participation, access to information, access to justice, environment, privatisation, Aarhus Convention

\section{The State, the Public and the Corporate Sector}

In most countries, law and policy for ensuring the protection of human health and the environment rely heavily on governments and public administrations. Different branches and levels of governmental administrations are mandated to supervise and control harmful activities, hazardous chemicals, nature protection, extraction of natural resources, and waste management. In part, this mandate builds on the welfare paradigm of state governance, whereby the public administration seeks its legitimacy in the promotion of development and sociability. ${ }^{1}$ While references to the "welfare state' are perhaps generally less fashionable today than some years ago, the expectation that the state and public administration ensure the protection of human health and the environment - and indeed promote sustainable development - remains. The entailed duty of this expectation for the state and public administration has even been reinforced in human rights law. ${ }^{2}$ Even so, the protection of human health and the environment not

\footnotetext{
Professor of environmental law at Stockholm University, and Chairperson of the Aarhus Convention Compliance Committee. The views in this article are those of the author personally and are not intended to represent those of the Aarhus Convention Compliance Committee.

B. de Sousa Santos, Toward a New Common Sense: Law, Science and Politics in the Paradigmatic Transition (1995), at 81.

2 On human rights and environment protection in general, see e.g. D. Shelton, Draft Paper on Human Rights and Environment: Past, Present and Future Linkages and the Value of a Declaration, Paper presented at UNEP and OHCHR High level Meeting on the New Future of Human Rights and Environment: Moving the Global Agenda Forward, Nairobi, 30 Nov.-1 Dec. 2009, available at <www.unep.org> (Last visited 1 October 2011); and P. Birnie et al., International Law and the Environment (2009), at 271-302. The human rights dimension of access to water is analysed by S. McCaffrey, 'The Human Right to Water', in E. B. Weiss et al. (eds.), Fresh water and International Economic Law. (2005), at 93. E. Hey, 'Distributive justice and procedural fairness in global water law', in J. Ebbesson \& P. Okowa (eds.), Environmental Law
} 
only depends on the public administration; it is also shaped by the rights, responsibilities and powers of members of the public, as well as the corporate sector, in the performance, control and decision-making related to environmental activities.

This article focuses on the power relation between the public administration, members of the public, including civil society organisations, and the corporate sector in environmental matters. More specifically, it examines the tension between two developments of environmental governance in the last decades: (i) the strengthening of participatory rights of members of the public in environmental decision-making, and (ii) the privatisation and outsourcing of resources, services and functions related to natural resources and the environment. The main question is how privatisation affects the rights of members of the public to participate in policy-making and decision-making in environmental matters.

Drawing on the welfare paradigm of state governance, human rights conceptions and straightforward environmental arguments, ${ }^{3}$ the importance of public participation in environmental decision-making has been widely acknowledged in national and international contexts. The global dimension of this endorsement is best illustrated by the 1992 Rio Declaration on Environment and Development:

Environmental issues are best handled with the participation of all concerned citizens, at the relevant level. At the national level, each individual shall have appropriate access to information concerning the environment that is held by public authorities, including information on hazardous materials and activities in their communities, and the opportunity to participate in decision-making processes. States shall facilitate and encourage public awareness and participation by making information widely available. Effective access to judicial and administrative proceedings, including redress and remedy, shall be provided. ${ }^{4}$

Although the Rio Declaration did not impose legal obligations on states, it became instrumental for the development of national laws as well as international law on public participation in environmental matters. In particular, the participatory rights acknowledged in the Rio Declaration framed the negotiations of the 1998 UNECE Convention on Access to Information, Public Participation in Decision-making and Access to Justice in Environmental Matters (Aarhus Convention). ${ }^{5}$ The Aarhus Convention, applicable to more than 40 states in Europe and Central Asia and the European Union, sets minimum standards for public participation in environmental matters. It follows the approach of the Rio Declaration in addressing situations where members of the public claim rights - concerning access to information or participation - against the public administration. Moreover, as revealed by the full title of the Aarhus Convention, it confirms that access to information and access to justice are embedded parts of public participation in environmental decision-making.

In parallel to the Aarhus Convention, international human rights bodies in Europe, the Americas and Africa have increasingly confirmed the human rights dimension of access to information, participatory rights and access to justice in environmental contexts. In doing so, they have applied provisions on the right to a satisfactory environment (where

and Justice in Context (2009), at 351-370, considers the recognition of a right to access to water, also as a human right, a sign that international water law is moving beyond merely inter-state relations towards a 'global water law'.

J. Ebbesson, 'The Notion of Public Participation in International Environmental Law', 8 Yearbook of International Environmental Law 1 (1997) at 51, 62-81

1992 United Nations Declaration on Environment and Development, UN Doc. A/CONF.151/26/Rev.1, 13 June 1992; 31 International Legal Materials (1992) 876, at Principle 10.

Convention on Access to Information, Public Participation in Decision-making and Access to Justice in Environmental Matters, 25 June 1998, reprinted in 38 International Legal Materials 15 (1999). The Aarhus Convention entered into force 30 October 2001. More than 40 states and the European Union are parties to the Convention. The Convention text and related documents can be found at $<$ www.unece.org/> (Last visited 1 October 2011). 
acknowledged) and the right to a fair trial, but also construed the right to respect to privacy and the right to property, so as to include a right of access to information, participation in decision-making and access to justice. ${ }^{6}$

The notion of public participation in environmental decision-making thus presupposes a responsibility on the government and the public administration to take an active role in protecting human health and the environment. Yet, it also reveals, if not an actual distrust in government, cognisance that the public administration cannot effectively or legitimately carry out these functions without due transparency and control, and the participation of members of the public in decision-making procedures.

Privatisation - the transfer of natural resources, environmental services or even of decision-making and supervisory functions from the public administration to private entities - challenges this power constellation and these claims of members of the public against the public administration. The use and control of natural resources and the performance of environmental services and functions pertain to public interests, values and wealth, and privatisation shift 'the arbiter of value from a political process focused on defining collective ambitions and aspirations to an individual deciding whether something is good in his or her own (more or less selfish, hedonistic, and materialistic) terms'. ${ }^{7}$ This has been described as a 'privatisation of environmental law', signifying how public decision-making processes are 'eroding under the influence of property rights doctrines, market devolution and commercial imperatives'. ${ }^{8}$

Spurred by ideological drives, but also motivated in terms of effectiveness and efficiency, the economic rationale behind privatisation is the trust in free market principles to address environmental problems. Put simply, such 'free market environmentalism' is based on the assumption that clearly defined and enforceable property rights will achieve the best possible allocation of resources, regardless of the environmental context. ${ }^{9}$ While privatisation of resources, services and functions relating to the environment as well as the underlying assumptions of 'free market environmentalism' have been criticised, ${ }^{10}$ this approach has had a huge impact on environmental policies and governance. Already in the 1960s and 1970s some governments made commons and public resources - for instance forests, minerals, fish and water - subject to rights with proprietary elements, but privatisation of natural resources and of services relating to these resources became increasingly prevalent in line with the neoliberal ideologies in the 1980s and 1990s. In the global context, the International Monetary Fund (IMF) was a major force in pushing for privatisation and liberalisation as part of its lending policy. ${ }^{11}$. This approach is also discernible in the free market restructuring promoted in new democracies by multilateral development banks and private banks. ${ }^{12}$

So we see two parallel - albeit neither very clear nor straightforward - developments with an impact on environmental policies, performance and governance: expanded participatory rights in environmental decision-making, and expanded privatisation of

\footnotetext{
See e.g. C. Redgewell, 'Access to Environmental Justice', in F. Francioni (ed.), Access to Justice as a Human Right (2007), at 153-175; Shelton, above n. 2; and J. Ebbesson, Draft Paper on Participatory and Procedural Rights in Environmental Matters: State of Play, Paper presented at UNEP and OHCHR High level Meeting on the New Future of Human Rights and Environment: Moving the Global Agenda Forward, Nairobi, 30 Nov.-1 Dec. 2009; available at <www.unep.org> (Last visited 1 October 2011).

M. H. Moore, 'Introduction [to the Symposium: Public Values in an Era of Privatization]', 116 Harvard Law Review 5 (2002-3) at 1215.

8 B. J. Richardson, 'Changing Regulatory Spaces: the Privatization of New Zealand Environmental Law', in K. Bosselmann and B. J. Richardson (eds.), Environmental Justice and Market mechanisms: Key Challenges for Environmental Law and Policy (1999), at 209.

T. L. Anderson \& D. R. Leal, 'Free Market versus Political Environmentalism', 15 Harvard Journal of Law \& Public Policy 2 (1992) at 297.

10 See e.g. P. S. Menell, 'Institutional Fantasylands: from Scientific Management to Free Market Environmentalism', 15 Harvard Journal of Law \& Public Policy (1992) at 489, criticising the implicit assumptions of 'free market environmentalism'.

11 For a critical account of the IMF lending policies, not least with regard to privatisation in developing countries, see J. Stiglitz, Globalization and it Critics (2002), at 54-59, who also, at 50-51, points to the lack of interest of the IMF for public participation, transparency and government accountability in the borrowing countries.

${ }_{12}$ M. Mason, 'Information Disclosure and Environmental Rights: The Aarhus Convention', 10 Global Environmental Politics 3 (2010), at 10, 13.
} 
natural resources, services and control functions relating to the environment. While the transfer of resources, services and public functions to private entities risks reducing the influence of members of the public against the private corporation and the public administration, the many means and forms of privatisation affect the scope and rights of public participation and influence - and thus the forms of governance - in different ways.

In this examination, the Aarhus Convention is used as the reference. This requires some proviso. While the Aarhus Convention is regional in scope, it also influences discourse on public participation concerning environmental matters outside Europe and Central Asia. So, by focusing upon the Aarhus Convention, rather than some individual states, it is possible to make more general conclusions on the impact of privatisation on participatory rights in environmental contexts. Yet, my conclusions essentially depend on the conception of the Aarhus Convention, in particular its broad definition of 'public authority', which also includes certain situations where private entities perform public functions or services. ${ }^{13}$ This conception of 'public authority', which is further described below, makes the Aarhus Convention surprisingly resilient to privatisation, since many of the participatory rights that it sets out remain in effect even if a public service or function is transferred to a private unit. If it were not for this broad framing, privatisation would have a far more adverse impact on the participatory rights.

The crucial concepts and minimum standards for access to information, participation in decision-making and access to justice within the Aarhus Convention are further described in Section 2, followed by a discussion of the scope and forms of privatisation in the Aarhus Convention context in Section 3. Sections 4-6 proceed to analyse how privatisation affects the participatory rights of the Aarhus Convention. The main findings and overall conclusions concerning whether the Aarhus Convention withstands privatisation are given in Section 7. Yet, the effects of privatisation not only depend on the Aarhus Convention standards and concepts alone, but also on the domestic legal framework surrounding privatisation, i.e. the extent to which domestic regulations, procurement contracts and other normative structures frame the duties and expectations of the private entity in charge of the service or function.

\section{The Aarhus Convention}

The Aarhus Convention does not follow the rights-based language of the European Convention on Human Rights. Its rationale is nevertheless rights-based; it is to ensure minimum procedural and participatory rights for members of the public, and it draws considerably on international human rights thinking. ${ }^{14}$ It also adapts and develops human rights concepts to environmental contexts, e.g. by relaxing the link to individual rights and by bestowing standing to environmental interest groups. ${ }^{15}$ Moreover, the Convention provides the legal basis for the Aarhus Convention Compliance Committee, which was established at the first meeting of the parties and is without precedence in international environmental agreements. ${ }^{16}$ The compliance mechanism combines elements of international human rights regimes, in particular by allowing communications on non-compliance by members of the public, and compliance mechanisms under other international environmental agreements. ${ }^{17}$ Due to its capacity for considering complaints

\footnotetext{
13 Aarhus Convention, Article 2(2).

Although the Aarhus Convention does not refer to human rights, the rights-based rationale is revealed in Article 1 of the Convention as well as in several paragraphs of the preamble, where references are made to the different rights and to other documents with some human rights elements. See UNECE, The Aarhus Convention: An Implementation Guide (2000), at 29: 'The most remarkable thing about Article 1 is that it clearly states that the Aarhus Convention is about basic human rights - the rights of every person'.

15 Ebbesson, above n. 3, at 55-59.

16 Article 15. The Compliance Committee was established by Decision I/7 of the First meeting of the Parties in Lucca, 21-23 Oct. 2002; see Report of the First Meeting of the Parties, Addendum, Review of Compliance, UN Doc. ECE/MP.PP/2/Add.8, 2 April 2004.

17 The features and work of the Compliance Committee is described by V. Koester, 'Review of Compliance under the Aarhus Convention: a Rather Unique Compliance Mechanism', 2 Journal of European Environmental \& Planning Law (2005) 31.
} 
by members of the public, the Aarhus Convention Compliance Committee has received more cases concerning non-compliance than any other compliance committee under any international environmental agreement. On the basis of these communications, the Compliance Committee makes findings on whether the party concerned is in compliance with the Aarhus Convention. ${ }^{18}$

The Aarhus Convention parties shall ensure that the public has access to environmental information held by public authorities. This includes not only information on the state of human health and safety and on the state of the environment, but also information about factors that affect human health and the elements of the environment, such as relevant substances, activities, administrative measures, policies, legislation, plans and programmes. ${ }^{19}$ When such information is requested, there is a presumption of access, and the public authority can only deny access on certain listed grounds (e.g. if the disclosure would adversely affect confidentiality of the proceedings of public authorities, international relations, the confidentiality of commercial and industrial information, and intellectual property rights). There are some exceptions to these grounds for refusal, and generally these grounds must be interpreted in a restrictive way, taking into account the public interest served by disclosure. ${ }^{20}$ The Compliance Committee has dealt with several communications where members of the public have complained that the party concerned did not provide access to information in accordance with the Convention, e.g. by ignoring or wrongfully denying requests for information. ${ }^{21}$

Although the right to access information applies to the information that is held by the authority in question, the Convention parties are required to ensure that public authorities possess and update environmental information that is relevant to their functions, and that they make such information available to the public in a transparent manner ${ }^{22}$ As pointed out below, in Section 4, this is also important in cases where private entities are in charge of services and functions related to the environment. In addition, the Convention parties shall establish nationwide, publically available systems of pollution inventories and registers in electronic databases. ${ }^{23}$ This obligation is further developed and specified by the 2003 Protocol on Pollutant Release and Transfer Register. ${ }^{24}$

Moreover, to different degrees, members of the public shall be able to participate in decision-making procedures concerning specific activities and installations, plans, programmes and policies, as well as in the preparation of generally applicable regulations and normative instruments. The requirements are most detailed for decisions concerning the permitting of specific activities that may have a significant effect on the environment. For this type of decision-making, the Convention parties must ensure that the public concerned is informed about the decision-making procedure, that public participation is provided for when all options are still open, that members of the public are allowed to comment and opine on proposed activities, and that such comments are duly taken into account when a decision is made. ${ }^{25}$ To a considerable extent these same criteria apply to plans and programmes relating to the environment, ${ }^{26}$ whereas the requirements for public participation in the preparation of generally applicable regulations and normative

\footnotetext{
18 All findings and documentation can be found at the Aarhus Convention website: <www.unece.org/> (Last visited 1 October 2011).

19 Article 2, para. 3.

20 Article 4

21 See e.g. Aarhus Convention Compliance Committee, ACCC/C/2008/24 (Spain), where Spain was found in non-compliance with article 4, inter alia for ignoring requests for environmental information for three months, for failing to give reasons for the denial of access to information, and for imposing an unreasonable fee for copying documents. Rather similar findings on non-compliance with respect to access to information were made in ACCC/C/2009/36 (Spain). In ACCC/C/2009/37 (Belarus), Belarus was held in non-compliance with the Aarhus Convention for having failed to provide requested information.

22 Article 5, paras. 1 and 2.

23 Article 5, para. 9.

24 Protocol on Pollutant Release and Transfer Register, 21 May 2003, entered into force on 8 October 2009. For Protocol text, see <www.unece.org $>$ (Last visited 1 October 2011).

25 Article 6, paras. 2-9.

26 Article 7.
} 
instruments (not to be mixed with legislation) ${ }^{27}$ are much more vaguely stated. ${ }^{28}$ The Compliance Committee has, on several occasions, also considered communications concerning public participation in decision-making for specific activities, e.g. with respect to the public announcement of permit procedures and short time limits for participation. $^{29}$

While the mentioned minimum standards are set for public participation with respect to permits and decisions for special activities (including changes, extensions, reconsiderations and updates) ${ }^{30}$ plans and programmes, the Convention fails to address many other forms of environmental decision-making. For example, a great deal of effort was made to include provisions on public participation in decision-making on the marketing of genetically modified organisms, and an amendment to the Convention was later made to that effect, ${ }^{31}$ but there is no equivalent provision on public participation concerning the marketing of chemicals. Moreover, although some decision-making relating to emission trading, quota setting (e.g. fishing) and nature conservation may amount to a plan or programme under the Convention, none of these forms of decisionmaking is explicitly addressed.

Finally, members of the public shall have access to justice, i.e. to review procedures where decisions, acts and omissions can be challenged. The Aarhus Convention distinguishes between three broad categories of decision-making for which access to justice must be ensured, and the minimum requirements differ depending on the decision, act or omission to be reviewed. First, judicial review procedures are prescribed for refusals by public authorities to requests for information. ${ }^{32}$ Second, distinct minimum standards for access to justice are set out for decisions, acts and omissions by public authorities relating to permits and permit procedures for specific activities. ${ }^{33}$ Third, for other acts and omissions contravening provisions of national law relating to the environment, whether by private persons or public authorities, members of the public shall have access to judicial or administrative review procedures ${ }^{34}$ This includes reviews of, for instance, decisions on plans and programmes, nature conservation and the marketing of chemicals. While the convention parties retain different degrees of discretion in defining the group of persons with standing for the different decisions, acts and omissions, all review procedures, whether judicial or administrative, shall provide adequate and effective remedies, and be fair, equitable, timely and not prohibitively expensive. ${ }^{35}$ Access to justice has also been subject to several cases before the Compliance Committee, for instance with respect to access to review procedures for non-governmental organisations, costs of review procedures and effective remedies. ${ }^{36}$

\footnotetext{
27 The Aarhus Convention does not apply to bodies and institutions acting in a legislative or judicial capacity; cf. Article 2, para. 2.

29 In ACCC/C/2006/16 (Lithuania), the Compliance Committee concluded that Lithuania failed to comply with the Aarhus Convention because it did not inform the public in an adequate, timely and effective manner about the possibility to participate in the decision-making, for providing too little time for participation, and for making the developer rather than public authorities responsible for organising public participation. In ACCC/C/2009/42 (Slovakia), the Compliance Committee found that Slovakia had failed to comply with the Aarhus Convention by not providing for public participation when an old permit was updated and the conditions were changed. Public participation issues were also raised in the mentioned cases ACCC/C/2008/24 (Spain); and ACCC/C/2009/37 (Belarus); all available at <www.unece.org $>$ (Last visited 1 October 2011).

30 Article 6, paras. 1 and 10, and Annex I, paragraph 22.

31 Article 6, para. 11. The amendment of the Convention, i.e. Article 6 (bis) with Annex I (bis), was not yet in force when this article was written.

32 Article 9, para. 1.

Article 9, para. 2

Article 9, para. 3.

Article 9, para. 4

36 In ACCC/C/2005/11 (Belgium) the Compliance Committee held that if the jurisprudence on standing for NGOs of the Belgian Council of State were to continue, Belgium would fail to comply with the Aarhus Convention. The Compliance Committee found in $\mathrm{ACCC} / \mathrm{C} / 2008 / 33$ (UK) that by failing to ensure that the costs for all court procedures subject to article 9 are not prohibitively expensive, and in particular by the absence of any clear legally binding directions from the legislature or judiciary to this effect, the UK failed to comply with article 9 , paragraph 4 of the Convention.
} 
Access to information, public participation and access to justice are closely connected parts of the participatory regime provided by the Aarhus convention: access to information is a prerequisite for effective participation in policy-making and decision-making, and access to justice is important in ensuring that participative rights, including access to information, are complied with by the public administration. All three 'pillars' primarily concern relations between members of the public and the public administration.

Yet, what makes the Aarhus Convention potentially resilient to privatisation is in particular its broad conception of public authority:

(a) Government at national, regional and other level;

(b) Natural or legal persons performing public administrative functions under national law, including specific duties, activities or services in relation to the environment;

(c) Any other natural or legal persons having public responsibilities or functions or providing public services, in relation to the environment, under the control of a body or person falling within subparagraphs (a) or (b) above;

(d) The institutions of any regional economic integration organization referred to in article 17 which is a Party to this Convention. ${ }^{37}$

The definition reveals a functional approach to the meaning of public authority, whereby the functions of the entity (public functions, responsibilities or services), rather than the juridical status, are decisive. Thus, the Arhus Convention expanded the definitional scope of public authority, compared to, e.g. EU law, ${ }^{38}$ and it has subsequently influenced not only the laws of the parties, but also other international agreements. ${ }^{39}$ First, in addition to governmental bodies at different levels and different branches, the definition applies to natural and legal persons performing public administrative functions. This includes, but is not limited to, persons with such functions in the field of the environment (which is relevant, e.g. with respect to access to environmental information).$^{40}$ Second, also other natural or legal persons who have public responsibilities or functions, or who provide public services, in relation to the environment, and under public control, are considered public authorities under the Convention. ${ }^{41}$ While 'public responsibilities, functions or services' indicate a broader designation than 'public administrative functions', this only applies 'in relation to the environment'. Among such entities are community-owned as well as privately owned public service providers. They include private providers of public services where residents may be obliged to pay a fee, e.g. for water supply or waste collection, and entities performing environment-related public service under regulatory control. ${ }^{42}$

The broad definition of public authority and the reach of the review procedures to some acts and omissions of private persons are critical for the participatory rights in situations where resources, functions and power are privatised, and where the decisions, acts and omissions of private entities affect common and public interests. Of course,

\footnotetext{
37 Article 2, para. 2.

38 The then applicable Directive 90/313/EC on Freedom of Access to Information on the Environment,

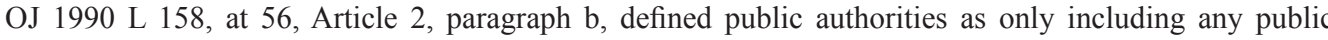
administration at national, regional and local level. Yet, according to article 6 of the Directive, the member states were obliged to ensure that also such information held by 'bodies with public responsibilities for the environment and under the control of public authorities' was made available. The definition of public authority was later changed so as to accord with the Aarhus Convention by Directive 2003/4/EC on Public Access to Environmental Information and Repealing Council Directive 90/313/EEC, OJ 2003 L 41, at 26, Article 2, para. 2.

39 E.g. the 1999 Protocol on Water and Health to the 1992 Convention on the protection and Use of Transboundary Watercourses and International Lakes, reprinted in 29 Environmental Policy and Law 4, (1999), at 200, Article 2, para. 12.

40 UNECE, above n. 14, at 32.

41 Article 2.

42 UNECE, above n. 14, at 33. As held by the Compliance Committee, in ACCC/C/2004/4 (Hungary), paragraph 10, a publically owned company established for the construction of highways also qualifies as a public authority under the Aarhus Convention.
} 
this broad and functional notion of public authority in the Aarhus Convention is due to the concerns during the negotiations regarding the effects of privatisation on human health and the environment. ${ }^{43}$ Still, one can question why the Convention does not take an even broader approach to private entities, in particular with respect to access to environmental information. Presently, as set out in the Aarhus Convention, the direct right of access to information held by private entities only applies when these private entities act as a public authority, whereas direct environmental information disclosure by corporations is only tackled by voluntary means (through eco-labelling and ecoauditing). ${ }^{44}$ An alternative approach would be to allow members of the public to request environmental information directly from any private or public entity. This approach was taken by Norway when implementing the Aarhus Convention: the Norwegian Act on Environmental Information sets out not only a right to request information held by public authorities, but also a right to directly request environmental information held by a public or private entity, related to its activity and its product. ${ }^{45}$

The application and effectiveness of the Aarhus Convention in cases of privatisation are not only linked to the broad definition of public authority. The access to justice 'pillar' also covers acts and omissions by private persons which contravene provisions of national environmental law, regardless of whether the private persons act as public authorities. ${ }^{46}$ Moreover, the effects of privatisation on participatory rights depend on the general legal setting in which the Aarhus Convention standards apply. Therefore, to keep up with the minimum standards of the Convention, ${ }^{47}$ such transfers may have to be accompanied by regulations or conditions in contracts of procurement or concession, so that the private actor in charge of the resource or service is obliged to act with due respect to the public values and interest at stake.

The Aarhus Convention and the European Convention on Human Rights, with their respective institutional setting, are the main drivers for participatory rights in Europe, with both legal frameworks supported by the law of the European Union. Outside Europe, international law on public participation is more fragmented and based on some regional human rights institutions (in Africa and the Americas) and some regional environmental agreements (North America, Africa and the ASEAN region). ${ }^{48}$

\section{Privatisation}

The means and forms of privatising a resource, business, facility, service or function, and the legal setting of the transfer, affect the scope of public control, including the exercise of the right to public participation. Ownership can be transferred from the public sector to the private sector, e.g. by share issue or asset sale, in part or in full. Services and functions may be outsourced, sub-contracted through public procurement, concessions or allocations of quotas, and carried out through private-public partnerships. ${ }^{49}$ In some cases, while the resource or facility remains public, private entities are in charge of the

\footnotetext{
43 UNECE, above n. 14, at 33, and M. Lee and C. Abbot, 'The Usual Suspect? Public Participation Under the Aarhus Convention', 66 Modern Law Review 1 (2003), at 80, 89, noting that the Aarhus Convention has attempted to make clear that privatisation cannot take public services or activities out of the realm of public involvement, information and participation.

${ }_{44}$ Article 5, para. 6. M. Mason, above n. 12, at 14 sees this as 'keeping within market liberal notions of regulatory action, [where] the Aarhus Convention restricts its direct obligations to public authorities'.

45 Norwegian Act 2003-05-09 No. 31 on the Right to Environmental Information and Participation in Public Decision-Making Processes of Importance for the Environment (Act on Environmental Information). 46 Article 9, para. 3.

47 A Convention party may maintain or introduce more generous rights to access to information, participation in decision-making or access to justice. Cf. Article 2, para. 5.

48 See: above n. 2 and n. 6.

49 See e.g. J. Freeman, 'Extending Public Law Norms Through Privatization', 116 Harvard Law Review 5 (2002-3), at 1285, 1286-7, listing different forms of privatisation. Without linking privatisation to public participation, C. J. Redgwell, 'Privatisation and Environmental Regulation: Some General Observations', 15 Journal of Energy \& Natural Resources Law 34 (1997) at 33-34, notes the 'range of choice ... on a continuum from public ownership and control through to minimum public regulation of private industry', which, she argues, directly corresponds to the degree of government involvement.
} 
service or activity engaged in the resource. However, when examining the impact of transfers from the public to the private sector on participatory rights in environmental matters, the focus here is on what is privatised rather than on how the transfer is made. To this end, privatisation may refer to (with examples):

a) Natural resources and rights related to the exploitation of resources (sale of forests and minerals, allocation of fishing rights through quotas)

b) Facilities and installations (buildings, offices, infrastructure)

c) Public services (water and energy supply, transport, sewage treatment, and security)

d) Decision-making and control functions (supervision, auditing and certification schemes, and, more generally, corporate self-control)

e) Rule-making (self-regulation, voluntary codes of conduct, and corporate social responsibility)

f) Dispute settlement and judicial functions (arbitration and conciliation procedures).

Some allocations of rights to exploitation through concessions or quotas, although not labelled as privatisation, may entail similar effects, for instance when governments grant certain entities the right to extract the resources and thus enjoy the revenues. Whether these examples should be seen as privatisation depends on the conditions for the transfers, the extent to which they are subject to public regulations or restrictions, and whether the receiver of the right is obliged to 'pay back' through public fees or taxes, so that some of the revenues are transferred to the public domain. Such allocations may have a comparable effect for the scope of public participation as a transfer of ownership of a resource. ${ }^{50}$

The use of market-based instruments does not amount to privatisation, but it may also include features that resemble privatisation..$^{51}$ The creation of an emission trading scheme illustrates this. The shared element is the transfer of control from the public administration to the operator in deciding the amount of carbon dioxide or other pollutants to be released. It also engages private actors as controllers. Yet, if implemented correctly, emission trading does not do away with public administration. On the contrary, it requires comprehensive public administration, control and sanctions, but in a different manner from the traditional permit systems for the activities concerned.

Although privatisation does not in itself make the resources, activities or installations in question immune from public control, ${ }^{52}$ it still affects environmental governance more generally, not just in terms of public participation. When resources or services are privatised, they are put under ownership, some form of usufruct or control of private entities, and the government's control is thus reduced. As pointed out, privatisation shifts the arbiter of value from a process focusing on defining and meeting collective ambitions to a process more focused on achieving private interests. Privatisation thus confers strategic and economic powers on the corporation in charge of the resource and service, which may even be entitled to compensation if the government imposes strict requirements or restrictions on the use or operation..$^{53}$

Needless to say, there are cases where public control is neither effective, transparent nor provided through good governance. In such cases, where the public administrative

\footnotetext{
S0 See e.g. Richardson, above n. 8, who includes such measures and policy in 'the privatisation of environmental law'.

51 Richardson, above n. 8.

52 As pointed out with respect to energy policies, e.g. by A. Ronne, 'Alternative Approaches to Regulatory Agency structures and Powers: Eastern and Western Europe', 15 Journal of Energy \& Natural Resources Law 1 (1997) 41; and M.M. Roggenkamp, 'Implications of Privatisation, Liberalisation and Integration of Network Energy Systems', 15 Journal of Energy \& Natural Resources Law 1 (1997), 51, while privatisation and liberalisation may change the role of governments, privatisation requires adequate, and possibly new, regulation. See also Redgwell, above n. 49.

53 Moore, above n. 7.
} 
system is corrupt and obscure, public control and administration does not ensure a more just distribution than private schemes, and privatisation could even make the control and distribution of benefits more transparent. Yet, privatisation challenges the distribution of the benefits and revenues raised from the resource amongst the public, in part because of reduced public participation. Such distributive justice considerations are crucial from the point of view of public goods and public values, and should be included in any policy discussion on the transfer of assets, services or functions to a private entity. ${ }^{54}$

Privatisation of authority and transfer of administrative control functions to private entities are a special case. The transfer here does not concern a resource (or the use of it) or service that may still be subject to decision-making with public participation, but rather the decision-making itself. Such control functions can be transferred to the operator of the harmful activity itself, either through statutes or regulations, or by some form of voluntary self-regulation or management schemes. While private or quasiprivate standards may work effectively for specific issues, for reasons of legitimacy and transparency, they should essentially be used only to add to and complement public standards. ${ }^{55}$ Yet, voluntary schemes and instruments may also infuse new concepts, which are subsequently transformed and codified into mandatory schemes. ${ }^{56}$ Increasingly, private actors are also used as auditors or certifiers in the monitoring and verification of measures in environmental regulation. ${ }^{57}$

For the following analysis and discussion on privatisation and the three dimensions of public participation provided by the Aarhus Convention, a rough distinction is made between, on one side, privatisation of resources and services and, on the other side, privatisation of functions related to administrative decision-making and control.

\section{Privatisation and Access to Information}

The right of access to information under the Aarhus Convention refers to the kind of information ('environmental information') held by a public authority, not to specific authorities or to specific tasks of the authorities. Rather, any public authority holding environmental information shall provide it upon request, unless any ground for refusal applies. In principle, this right of access to information is not affected by a transfer of mandate or information from one level or branch to another within the public administration.

Due to the broad and functional definition of public authority in the Aarhus Convention, members of the public maintain the right to access to information also in many cases when a public service, responsibility or function is transferred to a private entity. However, while environmental information held by a governmental body - local, regional or central - should be available regardless of the task and function of the authority in question, the duty of the private entity to disclose environmental information may depend on its function and responsibility.

\footnotetext{
54 On different notions of justice in environmental context, not least with respect to public participation, see J. Ebbesson and P. Okowa (eds.) Environmental Law and Justice in Context (2009).

55 A view shared by J. Morrison and N. Roht-Arriaza, 'Private and Quasi-private Standard Setting', in D. Bodansky et al. (eds.), The Oxford Handbook of International Environmental Law (2007), at 498, 526.

56 One example is the environmental management and auditing systems. These were initially developed by private and quasi-private institutions, such as the International Standardization Organization. The European Community Regulation 761/2001/EC Allowing Voluntary Participation by Organisations in a Community Eco-management and Audit Scheme (EMAS), OJ 2001 L114/1, considerably draws on the ISO system, and is maintained as a voluntary management and auditing scheme. In Swedish law, however, parts of the non-binding managing schemes (e.g. record keeping on the allocation of responsibility and on the use of chemicals, and routines for continuous risk assessment) were transformed into the Environmental Code and related governmental ordinance as mandatory legal requirements on self-control of environmentally harmful activities. A brief survey of voluntary measures is found in OECD, Voluntary Approaches for Environmental Policy: Effectiveness, Efficiency and Usage in Policy Mixes (2003).

57 An optimistic account on the role of businesses in monitoring and enforcement is given by S.R. Ratner, 'Business', in D. Bodansky et al. (eds.), The Oxford Handbook of International Environmental Law (2007), at $807,822-824$, who sees economic advantages in business self-enforcement, while realising that such enforcement will be constrained when business see environmental regulations as limiting profits.
} 
As stated, the Aarhus Convention defines a public authority as including not only parts of the government, but also natural or legal persons performing public administrative functions, including duties, activities or services in relation to the environment. When such public administrative functions are carried out, the duty, activity or services need not relate to the environment as such. The right of access to information then only depends on the kind of information requested; it must be covered by the definition of environmental information. In addition, any other natural or legal person with public responsibilities or functions, or providing public services (even without administrative responsibilities or functions) in relation to the environment, and under public administrative control, is a public authority. Certainly, in practice the distinction between carrying out public administrative functions and other functions under public administrative control is far from clear-cut, and rather contextual. Yet, in many situations, this definition includes private corporations to whom resources, services and functions are transferred. ${ }^{58}$

The decisive issue when determining whether a private corporation amounts to a public authority, with the duty to disclose information, is the function or service it performs and the responsibility it has, rather than whether it owns the resource or facility in question. Thus, if a public entity responsible for supplying water or energy is privatised or if the service is outsourced to a private corporation, the corporation performing the public functions or services would, in many cases, amount to a public authority regardless of whether ownership to the water treatment facility, energy plant or related natural resources was formally transferred. When operating in this capacity, the environmental information held by the corporation shall be made available upon request for a member of the public, under the same conditions as if the service had been provided by a public body.

While in these contexts, privatisation does not seem to reduce the right to access to environmental information, this right is essentially limited to the information that is held by the public authority. Yet, the Aarhus Convention requires that public authorities possess and update environmental which is relevant for their function, and also make it publically available, ${ }^{59}$ and this also applies to private actors qualifying as public authorities.

The 2003 Protocol on Pollutant Release and Transfer Register to the Aarhus Convention (PRTR Protocol) obliges the parties to make information on releases or transfers of pollutants from a large number of activities publically and easily available through such registers. ${ }^{60}$ While such a register generally enhances the right to access to environmental information, it does not imply a right for members of the public to request information directly from the operators of activities with a bearing on human health or the environment. Rather, to the extent the PRTR Protocol enhances access to information with regard to a specific activity, it is because it imposes reporting requirements on operators of listed kinds of activities. These reports provide the basis for the register, which shall be publically available. ${ }^{61}$

The amount of information held by the entity much depends on national laws and requirements. If the governmental entity in charge of an environmental service is required to posses and update certain information or to carry out investigations or inspections where information is gathered, and these duties do not accompany the transfer of the service to the private corporation, this may result in less information being available for members of the public. The corporation in charge of the service may choose to gather less information than the previous, public operator, either because informationgathering is too costly or because it does not want the information to be available to members of the public. This approach is more likely if the corporation operates in a competitive branch.

The risk that privatisation of a service results in less information for the public can be reduced by an adequate legal framework (e.g. regulations, procurement or other contractual conditions) surrounding the transfer, and obliging the corporation in charge

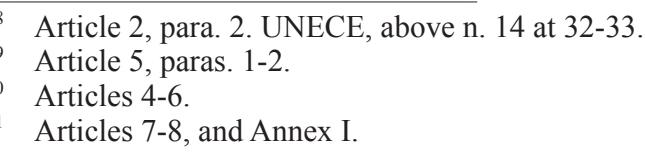


of the service to gather and provide certain environmental information related to its activity. Such a framework may also allow the government to retain some public control over the service.

The situation is not significantly different when functions related to administrative decision-making, supervision or public control are privatised. If private actors are mandated to perform certain functions in public participation procedures or contracted by supervisory authorities to carry out inspections or investigations relating to the environment, thus qualifying as public authorities under the Convention, the information gathered obviously amounts to environmental information. Private actors may also perform supervisory functions on the basis of regulations, for instance, as part of auditing and certification schemes. While some such schemes are voluntary, others are part of mandatory control systems. One example is the Designated Operational Entities (DOE) under the Clean Development Mechanism of the Kyoto Protocol to the UN Framework Convention on Climate Change. ${ }^{62}$ The DOEs are independent auditors accredited by the Clean Development Mechanism Executive Board, and their task is to validate project proposals or verify whether implemented projects have achieved planned greenhouse gas emission reductions. ${ }^{63}$ Similar functions are bestowed on accredited private units with regard to Joint Implementation projects and emission trading under the Kyoto Protocol.

In these cases the control function performed by private actors relates to the environment. Yet, in order to qualify as public authorities under the Aarhus Convention, with the accompanying duty to provide requested information, they must be considered as performing public administrative functions or as having public responsibilities or functions, while being under the control of a body or person with public administrative functions. In many situations this is the case ${ }^{64}$ and the information held by these entities shall thus be publically available to the same extent as if the functions were performed by a part of government.

While different from the previous cases, corporate self-control is also a kind of privatisation of environmental control functions, where certain tasks and responsibility (some of which draw on the voluntary management schemes of ISO 14000) are conferred on the operators themselves. Such self-control may be introduced in order to save public spending, but also as a means to make environmental management more effective. Unless the person in charge of the activity performs some service relating to the environment or broader control than its own unit, the requirement to control itself does not as such turn the operator into a public authority, with the duty to release its information directly to members of the public (unless required by national law). If the measures and control carried out by the corporation as part of its self-control are reported to the competent public authority, this environmental information shall be available upon request by members of the public. And again, if these measures are reported to a private auditor or certifier, as part of an auditing scheme, the auditor may qualify as a public authority as far as access to the information is concerned.

\footnotetext{
62 The Kyoto Protocol entered into force 16 February 2005. To a considerable extent, the modalities for the different flexible mechanisms have been developed through decisions by the Conference of the Parties, in particular the $7^{\text {Th }}$ meeting of the Parties in Marrakesh in 2001. See generally <cdm.unfccc.int $>$ (Last visited 1 October 2011).

63 Yet, as stressed by C. Voigt, 'Responsibility for the Environmental Integrity of the CDM: Judicial Review of Executive Board Decisions', in D. Freestone and C. Streck, Legal Aspects of Carbon Trading. Kyoto, Copenhagen and Beyond (2009), at 272, 280, the Executive Board, with the support of DOEs, is the institutional entity responsible for the environmental integrity of the CDM.

${ }^{64}$ A Designated Operational Entity under the Kyoto Protocol probably qualifies as a public authority by performing public administrative functions, as under article 2, paragraph 2(b) of the Aarhus Convention, rather than as having public responsibility or functions under the control of a 'public authority', as under article 2, paragraph 2(c). As mentioned, the private entity in charge of the control function performs under the supervision of the CDM Executive Board, which is part of an international treaty arrangement and not of a national government. In this context, the main task of the national authorities engaged in CDM projects, the Designated National Authorities, is to assess potential CDM projects to determine whether they will assist the host country in achieving its sustainable development goals, rather than supervising the Designated Operational Entities.
} 
The above analysis focuses on whether and to what extent privatisation circumvents the right to access to information set out by the Aarhus Convention. It appears that, formally speaking, in many cases where resources, environmental services or supervisory functions are transferred to private actors, the public's right of access to information remains. Yet, if no clear requirement applies to the information to be possessed by corporations with functions or services relating to the environment, they retain some leeway to decide on whether certain information, beyond the Aarhus Convention standards, should be kept or collected. In such cases, not least when corporations in charge of services compete with other private actors, they may be less compelled to gather and systematise information if they risk having to make it publically available.

Another negative effect of privatisation on transparency may be that the private entity holding the information will more actively obstruct access to information and refuse disclosure, even when the grounds for refusal are not met. Even if the person requesting the information would then be entitled to have the information, and would have access to an adequate review procedure before a court or an administrative authority, for a variety of reasons he or she might still not be willing or able to pursue the review procedure.

Privatisation of a service may also affect the grounds for refusing access to information, in particular that disclosure would adversely affect the confidentiality of commercial or industrial information. Possibly, concerns regarding commercial secrets increase once a service that was previously provided by a public body is transferred to a private corporation. Can the corporation in charge of the service then argue that what was previously public should now qualify as confidential information? The scope of that claim should be rather limited, since the grounds for refusing request must be interpreted in a restrictive way, taking into account the public interest served by disclosure. ${ }^{65}$ Even so, further national regulation may have to be adopted in order to ensure that the scope of information is not reduced by privatisation. ${ }^{66}$

\section{Privatisation and Public Participation in Decision-making}

Since access to information is a prerequisite for effective participation in decisionmaking, reduced access as a result of privatisation also affects the possibilities for effective public participation. Yet, privatisation affects the scope for public participation in decision-making differently than that of access to information. Whereas for access to information the decisive question is whether the private entity in charge of the resource, service or function, amounts to a 'public authority' under the Convention, for the scope of public participation the issue is rather what is transferred from the public to the private sectors. In this respect, privatisation of a resource or service also entails different effects on public participation than a transfer of the decision-making function itself.

The consequences of privatisation for public participation in decision-making are premised by two features of the Aarhus Convention. First, the Convention applies to decision-making by public authorities, not to any environmental decision-making by the operators of the activities themselves. Thus, strategic, marketing or other commercial decisions, that corporations make routinely and continuously, are not subject to public participation, although these decisions may have a significant impact on public health or the environment (though this is also the case when such activities are performed by public bodies). Second, instead of addressing all forms of environmental decision-

\footnotetext{
65 Article 4, paragraph 4.

66 In ACCC/C/2004/4 (Hungary), the Compliance Committee, taking note of the fact that a company established by legislation for the construction of express highways was state-owned and would therefore fall under the definition of public authority in Article 2, paragraphs 2(b) and 2(c), held that 'this in itself limits the scope of application of the commercial confidentiality exemption' Yet, it is not clear whether 'this in itself' refers to the fact that the company was established by legislation and state-owned, or to the mere fact that the company qualified as a public authority, which could be the case also for privately owned companies.
} 
making by public authorities, the focus of the Convention is limited to three broad categories of decision-making: specific activities; plans, programmes and policies; and general regulations and other forms of legally binding and normative instrument.

The most detailed minimum standards for public participation, described in section 2, apply to decisions on proposed specific activities that may have a significant effect on the environment. These requirements are mandatory for all decision-making on whether to permit proposed activities listed in the Convention, for instance, energy installations (e.g. thermal and nuclear power plants, and dams), production and processing of metals, mineral industries, chemical industries, waste management, major activities with water abstraction, and large scale infrastructure projects (railways, motorways, power lines, pipelines etc.). The standards for public participation also apply to other decisions on proposed activities that may have a significant effect on the environment. ${ }^{67}$

In these cases, the requirements for public participation do not depend on whether the proposed activity is operated or owned by a public or private unit. What matters for the scope of public participation is the kind of proposed activity, and, put simply, the fact that the activity in question may have significant effects on the environment. This means that members of the public shall be granted the same right to participate in the decision-making procedure regardless of whether the mineral, the installation or the service in question is owned or operated by a branch of government or by a private corporation. In that respect the Convention is neutral to ownership or privatisation.

Yet privatisation of a resource or service may, in more subtle ways, affect the scope for the decision-making procedure, and thus indirectly public participation as well. Operators of proposed activities will have the privilege of deciding on what activities to propose, i.e. on the size of the installations, the safety measures, and, possibly, the conditions for the operation of the activities. The operators may also be more or less engaged in drafting the environmental impact assessment report for the activities. Hence, the transfer of ownership or of the right to perform a service may affect the way the proposal is made. In this respect, the operators are privileged by the possibility of framing issues to be considered in the decision-making procedure. Corporations also operate under a commercial logic where profit-making is at the core, and this may affect the preparedness for financing safety measures. Still, it is fundamental to the Aarhus Convention that, first, the permit is issued by a public authority and, second, that the participatory rights prescribed are not affected by the public or private status of the operator or the ownership of the resources.

The effects of privatisation are rather similar for decision-making on plans and programmes. Plans and programmes often comprise activities, installations and services performed and operated by private as well as public bodies. For sure, privatisation shifts the strategic powers related to the resource, service and function, and that may also affect the initiatives and lobbying for new plans and programmes. Even so, privatisation does not circumvent the participatory rights as such when plans and programmes are to be decided. The Aarhus Convention requirements for plans and programmes draw on those for specific activities, with the effect that early public participation, within reasonable time-frames, shall be ensured when all options are open, and the outcome of the participatory procedures shall be taken into account. ${ }^{68}$

The situation is different when the decision-making, supervisory or controlling function in itself, rather than the resource or service, is privatised. The private entity is then not be subject to the decision-making but in charge of it. For decision-making that is covered by the Aarhus Convention, a public authority is in charge and expected to make its decision on the basis of the different participatory procedures; ${ }^{69}$ the presumption would be that the public authority is part of the government. Still, the Aarhus Convention does not exclude the possibility of delegating certain responsibilities in the decision-making procedure to different bodies and private actors. When private actors carry out functions in public participation procedures, then, according to the Compliance Committee:

\footnotetext{
67 Article 6, para. 1(b), and Annex I.

68 Article 7.

69 All articles on public participation, i.e. Articles 6-8, refer to public authorities.
} 
[s]uch bodies or persons, performing public administrative functions in relation to public participation in environmental decision-making, should be treated, depending on the particular arrangements adopted in the national law, as falling under the definition of a "public authority" in the meaning of article 2, paragraph 2(b) or 2(c). ${ }^{70}$

There are nevertheless limits as to the means and forms for making private actors responsible for the procedure. For instance, it is not compatible with the Aarhus Convention standards to rely solely on the applicant ('the developer') when providing for public participation or information about the procedure:

Indeed, it is implicit in certain provisions of article 6 of the Convention that the relevant information should be available directly from public authority, and that comments should be submitted to the relevant public authority.... Accordingly, reliance solely on the developer for providing for public participation is not in line with these provisions of the Convention. ${ }^{71}$

Accordingly, in any decision-making covered by the Aarhus Convention, functions related to public participation can only be delegated by the authority in charge of the decision to other bodies or private persons to the extent that sufficient impartiality is ensured to guarantee proper conduct during the public participation procedure. ${ }^{72}$ Moreover, even if a function is delegated to a private actor, all standards for public participation apply in full.

As mentioned, some environmental decision-making is not covered by the Aarhus Convention, for instance supervisory decisions and auditing and certification schemes. Such decision-making may involve the public administration as well as private actors, but the Convention does not set minimum standards for public participation and, accordingly, does not prevent or restrict the means or forms of outsourcing decisionmaking. Even so, if private entities are in charge of parts of such decision-making (as auditors or certifiers), they would still act as public authorities under the Convention, even though the Convention does not set standards for the procedures. ${ }^{73}$ These private entities must therefore comply with other parts of the Convention, for instance in providing the requested environmental information, as well as in assisting and providing guidance to the public in seeking access to information and in facilitating participation in decision-making. ${ }^{74}$

Thus, while the Aarhus Convention standards for public participation also remain applicable when resources, services and even decision-making functions are transferred to private entities, the situation is less consistent with regard to transfers of decision-making functions. As regards decision-making covered by the Convention, any delegation of such a function must ensure that the private persons act with due impartiality and as a public authority. As for the environmental decision-making not covered by the Convention, its standards can apply analogously, so as to ensure good governance in environmental administration. However, in such instances the Convention does not do much to constrain privatisation, and this is only slightly compensated for by its standards on access to justice, with broader coverage.

70 Aarhus Convention Compliance Committee, ACCC/C/2009/37 (Belarus), para. 78.

71 Aarhus Convention Compliance Committee, ACCC/C/2006/16 (Lithuania), para. 78.

72 Aarhus Convention Compliance Committee, ACCC/C/2009/37 (Belarus), paras. 77-81. As described in this case, paragraphs 22-29, it seems to be a general feature in some of the former socialist countries that the environmental impact assessment procedure (the acronym is OVOS, which could be directly translated to 'assessment of impact upon the environment'), including the procedure for public participation, is carried out by the applicant, which may be a private or public entity in charge of the operation. The findings of the Compliance Committee reveals that such procedures may fail to comply with the Convention.

${ }_{73}$ The DOEs in CDM projects under the Kyoto Protocol, described in Section 4, may also be considered 'public authorities' under the Aarhus Convention, provided they carry out their administrative functions under the national law of an Aarhus Convention party; cf. Article 2, para. 2, of the Aarhus Convention.

${ }^{74}$ Article 3, para. 2, and Article 4. 


\section{Privatisation and Access to Justice}

Privatisation accentuates the right of access to justice for members of the public. Even when privatisation is compatible with the Aarhus Convention, it engages public interests and public values, and shifts strategic powers with regard to public goods. Given that private entities may escape some public auditing and due political control when performing these services and function, the public's need for effective and adequate and fair and equitable - review procedures is clear. As it turns out, within its scope, the Aarhus Convention is reasonably well-structured towards meeting the challenges that privatisation presents for access to justice.

First, it precludes almost any attempt to privatise the review procedures as such, with the possible exception of arbitration, unless this review procedure is in itself subject to appeal. For decisions, acts and omissions relating to information request and decisionmaking for specific activities, the review procedure must be performed by a court or a court like body of law. But even for other acts and omissions, the review procedures must be fair and equitable. ${ }^{75}$ This requires independence and impartiality on the part of reviewing body, and should disqualify private corporations from functioning as the final review body in the scheme of access to justice.

Second, the scope for access to justice under the Aarhus Convention is considerably broader than the range of environmental decision-making for which it prescribes public participation standards. Access to justice must be granted not only for decisions, acts and omissions by private entities when performing as public authorities under the Convention, but also in other situations where acts and omissions by private persons may contravene national laws relating to the environment. ${ }^{76}$

The right of access to environmental information, even when held by a private corporation acting as a public authority, comprises a right to a review procedure before a court or court like-body. ${ }^{77}$ Thus, the person who thinks that his or her request for information was ignored or wrongfully refused by the private corporation in charge of a public environmental service shall be able to bring this decision to a court or court-like body of law. The court's decision must also be binding for a private entity performing as a public authority, and the court must have the requisite power to enforce a decision that the information be disclosed upon the private entity.

The right to participate in decision-making on specific activities also gives rise to access to justice. To that effect, members of the public concerned shall be entitled to challenge decisions, acts and omissions concerning a proposed specific activity in a review procedure before a court or court-like body of law. In contrast to the case of refused environmental information, the Convention parties are not required to grant standing to review procedures to just 'any person' who thinks the decision-making concerning specific activities decision was incorrect. Rather, they must ensure that 'members of the public concerned' with an interest or right affected by the decisionmaking can bring the case to judicial review. Convention parties have some leeway in defining what constitutes a sufficient interest or an impaired right, to entitle standing in a review procedure, but must do so consistently with the objective of giving the public concerned wide access to justice. In this respect, non-governmental organisations, meeting any requirements under national law, shall be deemed to have a sufficient interest to be entitled access to review procedures. ${ }^{78}$

The review procedure shall pertain to substantive and procedural legality, which may include permit conditions, the public participation procedure, and the environmental impact assessment. The review may also include the status of the operator of the proposed activity; for instance if the private entity is capable of running the activity. Generally speaking, however, whether the activity is proposed or operated by a public or private entity affects neither the scope of persons with access to the review procedure

\footnotetext{
Article 9, para. 4.

Article 9, para. 3.

Article 9, para. 1, which also requires an expeditious reconsideration procedure.

Article 9, para. 2.
} 
nor the scope of review itself. In other words, a transfer of a resource or a service from the public to the private sector does not impinge on the minimum standards for these review procedures.

A Convention party may apply a tiered and consecutive decision-making procedure for specific activities, and some parts of the procedure may be delegated to other bodies, including private persons qualifying as public authorities. Yet, the review system must embrace issues of substantive and procedural legality in all these parts. Thus, if an element or tier in this process is somehow privatised, the decisions, acts and omissions by the private person in charge of that part shall be reviewable. Such a review should include the very impartiality and capacity of the private person responsible for public participation procedures.

As mentioned in Section 2, access to justice shall be provided also with respect to other acts and omissions by private persons and public authorities that contravene provisions of national law relating to the environment. ${ }^{79}$ In particular, this gives members of the public a right to challenge acts and omissions by private persons, including corporations, even when they are not performing as public authorities under the Convention. Thus, even if the transfers of natural resources, services or functions to corporate entities do not turn them into public authorities under the Convention, they still cannot escape from being reviewable on the initiative of members of the public. While this may ensure adequate access to justice even in cases of privatisation, there are some limitations as to its reach.

First, the review procedures under this provision of the Aarhus Convention refer to acts and omissions contravening provisions of national law relating to the environment. While the reference to national law may not be so problematic in many situations where corporations are in charge of activities with an environmental impact, it still begs the question as to which provisions are included. For instance, to what extent do provisions in environmental laws that refer to the concerns for human health relate to the environment? And are all acts and omissions by corporations in charge of, say, water or energy supply, such that they may contravene provisions in the law relating to the environment?

Second, the Convention parties have some leeway for these procedures too, in defining which members of the public shall be entitled to trigger review procedures against corporations in charge of privatised natural resources or services. Yet, these 'criteria, if any, in national law ${ }^{80}$ may not be so strict that they effectively bar all or almost all members of the public, including environmental organizations, from challenging the reviewable act or omission in question. ${ }^{81}$ So in principle, for any act and omission by private persons which contravenes provisions in national law relating to the environment, some members of the public, including non-governmental organisations, shall be able to start a review procedure.

Third, while the routes for access to justice concerning access to information and decision-making related to permits for specific activities must be judicial, for all other acts and omissions the review procedures can be either judicial or administrative in nature. Even so, the general standards for access to justice - that the review procedures must provide adequate and effective remedies, and be fair, equitable, timely and not prohibitively expensive - also apply to any administrative review procedure (and apply regardless of whether the body in charge of the challenged decision, act or omission is private or public)..$^{82}$

Although the requirement of fairness and equity would preclude corporations from acting as review bodies of last resort, private entities can possibly perform certain functions in the review procedure under the control of the public administration. Even so, fairness and equity require considerable independence and impartiality of the reviewing body; this would generally disqualify corporations from being in charge of

79 Article 9, para. 3.

80 Id.

81 See Arhus Convention Compliance Committee, ACCC/C/2005/11 (Belgium), paras. 35-36; and ACCC/C/2006/18, (Denmark), paras. 29-30.

82 Article 9, para. 4. 
such functions. The possible exception is arbitration, which is a privatised, or quasiprivatised, form of dispute settlement. Arbitration would generally meet the criteria for independence and impartiality, and it could also be adequate under the Aarhus Convention for challenging acts or omissions by private persons which contravene provisions relating to the environment. One possible case for arbitration, at least in theory, would be if neighbours invoked private law remedies and request injunctive relief against an industry for nuisance. Even so, the diversity and public character of many interests involved would still make arbitration less suitable than other judicial or administrative procedures, where public interests can be better taken into account. Moreover, while arbitration is not generally prevented by the Aarhus Convention, the high costs usually involved in arbitration procedures could disqualify this route from providing access to justice in accordance with the Convention.

In sum, the room for privatising functions relating to access to justice and review procedures under the Aarhus Convention is very limited. Another general feature of the Aarhus Convention's access to justice standards is its broad coverage of acts and omissions by private actors for which review procedures shall be provided. This is important for ensuring access to justice also if and when assets, resources and powers are transferred from the public to the private sphere.

\section{Conclusion}

The scope for public participation in environmental decision-making, and the related rights to access to information and justice, are essential indicators of public control over public values. Public participation matters in itself for the legitimacy and effectiveness of environmental governance and decision-making. Privatisation affects the relation between public and private interests generally, including the distribution of burdens and benefits in society, the effectiveness and legitimacy of public affairs and environmental policy, and the strategy for promoting sustainable development. The consequences of privatisation for environmental governance go beyond the participatory rights examined in this assessment of the Aarhus Convention, but it is still important to consider whether these rights shrink as a result of the transfer of resources, services or functions from the public to the private sector.

The conclusions, and the concerns that privatisation may adversely affect the scope of publicly accessible environmental information, refer to situations where the Aarhus Convention standards are essentially respected. Yet, they do not imply that public administration is always transparent and legitimate, or that public management of services is always more transparent and effective or less corrupt than when such services are performed by private entities. On the contrary, numerous governments are all but transparent, and fail to meet the Aarhus standards. An argument could be made in such cases in favour of privatising certain services and functions in order to reduce corruption and even improve transparency.

The conclusions on the impact of privatisation on participatory rights in environmental matters depend greatly on how are these rights are defined in the Aarhus Convention itself. Due to the Convention's broad definition of public authority, private entities performing public administration functions, having public responsibilities or functions, or providing services in relation to the environment, while acting under administrative control, amount to being public authorities. Therefore, in many situations neither the Convention party nor the private entity in charge can escape the participatory rights set by the Aarhus Convention. The functional definition of public authority is well suited to the numerous legal systems with different combinations of public and private competences in environmental governance. The underlying notion is that the rights of members of the public to be part of decision- and policy-making and the control of compliance with environmental and other laws should not be affected by the outsourcing of public resources, services or functions. 
The broad notion of public authority is generally supported by the $40+$ Convention parties, including the European Union. ${ }^{83}$ Even so, this understanding of public authority must be taken into account when more general conclusions or comparisons are made concerning the impact of privatisation on public participation outside the context of the Aarhus Convention. Given another conception of public authority, such conclusions may be entirely different and the impact of privatisation considerably greater.

As with most international agreements, the Aarhus Convention is intended to address the laws of the Convention parties on rather specific matters, in this case the distinct standards on public participation, while disregarding most other parts of the legal systems. Yet it should be repeated that the effectiveness of participatory rights depends not only on formal compliance with the Aarhus Convention, but also on the general legal setting surrounding privatisation. Privatisation is not binary; it is a matter of degree. If resources and services are outsourced without conditions or regulations, the effect on participatory rights is likely to be more severe than if a private corporation performing the service is required to, for example, keep certain environmental information publically available and act with due public responsibility towards members of the public.

In most countries where the Aarhus Convention standards for public administration are adhered to, the means by which to ensure that the public administration is accountable for the adverse effects on human health and the environment are more effective than those in place for keeping the private sector accountable. To some extent, however, the Aarhus Convention helps to reduce this difference.

83 E.g. EU Directive 2003/4/EC on Public Access to Environmental Information, Article 2, para. 2, with the same definition (see above n. 38). 